NOTE

\title{
Effects of water light absorption properties of a radiographic film
}

\author{
Tsang Cheung ${ }^{1}$, Martin J Butson ${ }^{1,2}$, Peter K N Yu ${ }^{1}$ and Peter Metcalfe ${ }^{2}$ \\ ${ }^{1}$ Department of Physics and Materials Science, City University of Hong Kong, Kowloon Tong, \\ Hong Kong, People's Republic of China \\ 2 Department of Medical Physics, Illawarra Cancer Care Centre, Crown Street, Wollongong, \\ NSW 2500, Australia \\ E-mail: butsonm@iahs.nsw.gov.au
}

Received 26 June 2002

Published 3 October 2002

Online at stacks.iop.org/PMB/47/N279

\begin{abstract}
Photon beam dosimetry using Kodak extended dose range (EDR2) radiographic film can provide accurate and high spatial resolution information especially for areas such as IMRT dosimetry where a higher dose level (100-400 cGy) is often required to be delivered for verification. For such dosimetry checks, it may sometimes be useful to place the film in a tank filled with water during irradiation. The effects of water on the film when packaged and when removed from the packaging have been examined. Results have shown that the EDR2 film when supplied in the ready pack form is provided in water proof packages and no significant absorption effects are observed or measured on the film even after $48 \mathrm{~h}$ of soaking in a water bath. When the film is removed from the ready packs and exposed to water directly, various effects are seen. In the visible spectrum region, small variations (up to $3 \%$ ) in recorded optical density (OD) are recorded using a fluorescent light densitometer. These effects become much larger in the infrared region (e.g. $7.5 \%$ at $900 \mathrm{~nm}$ and $12.5 \%$ at $1000 \mathrm{~nm}$ ) and are wavelength dependent. The changes produced by the water are relatively independent of the exposure time to water from $5 \mathrm{~s}$ up to $1 \mathrm{~h}$ or whether the water exposure occurred.
\end{abstract}

\section{Introduction}

Film dosimetry in radiotherapy can depend on many parameters. Some of these include the energy or beam quality of the irradiation beam (Johns and Cunningham 1983, Yeo et al 1997, Sykes et al 1999, Kron et al 1998), whether the exposure is performed parallel or perpendicular to the film (Suchowerska et al 1999, 2001, van Battum and Heijmen 1995) or the chemistry involved in the processing of the film (Khan 1992). The visible and infrared absorption spectra of Kodak EDR2 film have been investigated to analyse the dosimetry characteristics of the film 
when influenced by the presence of water on the film surface. This has been performed before, during and after irradiation with $\mathrm{x}$-rays to provide quantitative effects produced by water on the film. Historically, infrared light sources were commonly used for radiographic film densitometers to avoid interference with the room lighting (Metcalfe et al 1997) More recently, visible light densitometers have become more widely used (Mersseman and De Wagter 1998) partly due to the introduction of radiochromic film dosimetry in radiotherapy where the optimal light source required for dosimetry should lie in the 'red' region of the visible spectrum. Thus a visible light densitometer can be used for both applications. We investigate the influence of water on the optical density absorption characteristics of the film in the visible and infrared wavelength region from $400 \mathrm{~nm}$ to $1100 \mathrm{~nm}$.

\section{Materials and methods}

Kodak extended dose range (EDR2) radiographic film was studied for effects of water on the visible and infrared absorption properties of radiographic film. The film was processed in a Kodak M35 X-Omat processor. The absorption spectra results were measured using a Shimadzu UV-160 UV-V-IR recording spectrophotometer. Its wavelength range is $300 \mathrm{~nm}$ to $1100 \mathrm{~nm}$ and has a spectral bandwidth of $3 \mathrm{~nm}$ with an accuracy of $\pm 0.5 \mathrm{~nm}$. Measurements were only made from $400 \mathrm{~nm}$ to $1100 \mathrm{~nm}$ to include the visible and infrared wavelengths. The film was held in a clear, quartz holding container which allows transmission of UV, visible and infrared radiation. Measurements were made in $10 \mathrm{~nm}$ intervals from $400 \mathrm{~nm}$ to $1100 \mathrm{~nm}$. Experiments to measure the effects of water on film dosimetry were performed in various steps. First, EDR2 ready pack film was placed in water baths for various lengths of time from 1 min up to $48 \mathrm{~h}$. Irradiations of $1 \mathrm{~Gy}$ and $2 \mathrm{~Gy}$ applied doses were given to the films, half prior to the water exposure and half after water exposure. The films were examined for optical density properties using the Vidar VXR-12 scanner and the Shimadzu photo spectrometer to measure any differences in optical density properties caused by the water bath. Secondly, EDR2 films were removed from their protective packets and directly soaked in room temperature $\left(20-22{ }^{\circ} \mathrm{C}\right)$ water baths for periods of $5 \mathrm{~s}$ up to $1 \mathrm{~h}$. This was performed before, during and after irradiation with high-energy photons. Optical density characteristics were measured to evaluate the effects of the water on film dosimetry. Note, the films that were exposed during irradiation were also soaked before and after irradiation due to the set-up and removal time of the film. To expose the film to water before irradiation, the films were taken out of their packaging and placed in the water bath in a dark room for the required length of time. They were then allowed to drip dry and placed back in the packaging and resealed with tape before irradiation in a solid water phantom to doses of $1 \mathrm{~Gy}$ and $2 \mathrm{~Gy}$. Films that were exposed to water after irradiation were irradiated in their original packaging in solid water, then removed and soaked in the water bath before processing. Care was taken when inserting wet films into the automatic film processor to reduce the risk of pressure damage to the films. This was done by placing the film into the developer by hand. To do this, the processor was opened and the film hand fed into the developer tank.

\section{Results and discussion}

Table 1 shows results of the measured optical density versus 'soaking in water' time for EDR-2 radiographic film. The $35 \mathrm{~cm} \times 43 \mathrm{~cm}$ film was soaked in room temperature in a water bath for the quoted time intervals fully submerged in the original ready pack envelopes. 
Table 1. Optical density measurements of water soaked ready pack EDR2 radiographic film.

\begin{tabular}{|c|c|c|c|c|c|c|}
\hline \multirow[b]{3}{*}{ Time (h) } & \multicolumn{6}{|c|}{ Optical density with applied dose } \\
\hline & \multicolumn{2}{|c|}{0 Gy $( \pm 0.01)$} & \multicolumn{2}{|c|}{1 Gy $( \pm 0.015)$} & \multicolumn{2}{|c|}{2 Gy $( \pm 0.025)$} \\
\hline & Before & After & Before & After & Before & After \\
\hline 0.25 & 0.230 & 0.235 & 0.740 & 0.740 & 1.25 & 1.25 \\
\hline 0.5 & 0.230 & 0.230 & 0.750 & 0.740 & 1.25 & 1.26 \\
\hline 0.75 & 0.235 & 0.235 & 0.740 & 0.745 & 1.26 & 1.25 \\
\hline 1.00 & 0.235 & 0.230 & 0.735 & 0.745 & 1.25 & 1.26 \\
\hline 1.5 & 0.230 & 0.230 & 0.735 & 0.740 & 1.26 & 1.25 \\
\hline 2 & 0.235 & 0.235 & 0.745 & 0.750 & 1.27 & 1.26 \\
\hline 12 & 0.235 & 0.230 & 0.740 & 0.750 & 1.26 & 1.26 \\
\hline 24 & 0.230 & 0.235 & 0.740 & 0.740 & 1.26 & 1.26 \\
\hline 48 & 0.235 & 0.230 & 0.735 & 0.745 & 1.26 & 1.26 \\
\hline
\end{tabular}

Following the water bath the films were irradiated with doses of $1 \mathrm{~Gy}$ and $2 \mathrm{~Gy}$ using $6 \mathrm{MV}$ x-rays and a $10 \mathrm{~cm} \times 10 \mathrm{~cm}$ field size. Results show that the presoaking of the film in the ready pack for up to 2 days before irradiation produces a negligible effect on the measured optical density of the irradiated film. Thus the ready pack film container can be considered waterproof in its original form. Upon close inspection of the ready pack film envelopes we noticed that most films examined seemed to be in an air-evacuated form, i.e. they were compressed with little if any air gaps within the packing materials. Six out of 100 films investigated however had notable air gaps or bubbles, i.e. small bubbles that could make a distinguished rise of 3-4 $\mathrm{mm}$ in the packaging over $1-2 \mathrm{~cm}^{2}$ area. The seemingly waterproof container makes the EDR-2 film in this form ideal for dosimetry purposes in a water phantom environment. We would recommend though that the film ready pack is inspected for airtight sealing and that the recommended $3^{\circ}$ tilt (Suchowerska et al 2001) to reduce the effects of parallel irradiation still be applied if radiation exposure is needed in a near parallel configuration.

In some cases for dosimetry it may be necessary to use the radiographic film in the environment of water and a protective coating cannot be applied. We have investigated the influence of water directly on the radiographic film before, during and after irradiation to assess the effects on the optical properties of the film after irradiation and processing. Table 2 shows the results for optical density of EDR-2 film which has been exposed to water for varying times before, during and after irradiation and compares the results to those of the film which has not been in contact with water (dry film). Results from table 2 indicate that the water does produce an effect on the optical density of the film as measured by a Vidar VXR-12 visible light densitometer. Results have shown that measured optical density for wet film is slightly smaller than dry film in the visible region where the Vidar scanner measures OD. This effect is relatively small, uniform and seems to be relatively independent of the time of the water exposure. That is $5 \mathrm{~s}$ exposure to water produces a very similar effect as in a $1 \mathrm{~h}$ exposure. There is only a statistically non-significant difference, an analysed by $t$-test between the films, which were soaked before, during or after irradiation. Thus the final results for optical density seem to be relatively independent of the time at which the water exposure occurred.

One important factor influencing the image production/optical density of the film when affected by water is the pressure applied to the film during automatic processing which can vary significantly as a result of water exposure. When the film has water on it, it can 'stick' 
Table 2. Measured optical density for film soaked in water and percentage variations from dry film.

\begin{tabular}{|c|c|c|c|c|c|c|c|}
\hline \multirow[b]{2}{*}{ In water } & \multirow[b]{2}{*}{ Time } & \multicolumn{3}{|c|}{$\mathrm{OD}(\%$ error $-2 \mathrm{SD})$} & \multicolumn{3}{|c|}{$\begin{array}{l}\text { Difference from dry film } \\
(\% \text { of net OD })\end{array}$} \\
\hline & & 0 Gy $( \pm 3.0)$ & $1 \mathrm{~Gy}( \pm 2.4)$ & 2 Gy $( \pm 2.6)$ & $0 \mathrm{~Gy}$ & $1 \mathrm{~Gy}$ & $2 \mathrm{~Gy}$ \\
\hline \multirow[t]{4}{*}{ Before } & $5 \mathrm{~s}$ & 0.226 & 0.717 & 1.230 & -2.0 & -2.8 & -3.3 \\
\hline & $30 \mathrm{~s}$ & 0.225 & 0.717 & 1.220 & -1.5 & -3.2 & -3.6 \\
\hline & $5 \mathrm{~min}$ & 0.229 & 0.720 & 1.215 & -2.0 & -1.9 & -3.2 \\
\hline & $1 \mathrm{~h}$ & 0.225 & 0.723 & 1.222 & -2.2 & -2.8 & -2.9 \\
\hline \multirow[t]{2}{*}{ During $^{\mathrm{a}}$} & $5 \mathrm{~min}$ & 0.227 & 0.738 & 1.220 & -2.6 & -3.1 & -3.8 \\
\hline & $1 \mathrm{~h}$ & 0.225 & 0.720 & 1.233 & -1.8 & -3.4 & -3.0 \\
\hline \multirow[t]{4}{*}{ After } & $5 \mathrm{~s}$ & 0.223 & 0.721 & 1.201 & -3.0 & -3.5 & -4.2 \\
\hline & $30 \mathrm{~s}$ & 0.228 & 0.719 & 1.210 & -1.4 & -3.5 & -3.3 \\
\hline & $5 \mathrm{~min}$ & 0.226 & 0.725 & 1.216 & -3.1 & -2.8 & -3.5 \\
\hline & $1 \mathrm{~h}$ & 0.228 & 0.722 & 1.213 & -2.9 & -3.0 & -3.4 \\
\hline
\end{tabular}

${ }^{a}$ Note. During irradiation also includes before and after time which includes the set-up and removal time.

(due to increased adhesive and cohesive forces) to the film insertion tray. When this happens, the automatic mechanical rollers, which pull the film through the developer, fixer, etc. apply a high pressure on the film in an uneven manner. This pressure directly affects the film's optical characteristics leaving a series of dark and light marks on the film. To avoid the effects, in our case, the wet films were inserted by hand into the developer without touching the insert tray to avoid putting any pressure on the film. This was achieved easily by removing the processor's top cover and directly placing the film in the developer tank which then automatically feeds the film through the other sections for final development. As a magnetic switch interlocks the processor's cover, an override magnet is required to be placed over the switch to allow the processor to operate with the cover removed.

Figure 1(a) shows a typical optical density versus wavelength spectral analysis over a spectrum of wavelengths for two films that are unexposed to radiation. One film was soaked in water for a $5 \mathrm{~min}$ period and the other was kept dry. Results show that the spectral response of the unirradiated films is relatively unchanged by the influence of water. The absorption properties of the two films as well as the differences are shown. Figure 1(b) shows a typical result for both radiation exposed films ( 2 Gy applied dose). The wet film was soaked for a period of $5 \mathrm{~min}$. Results show that both films produce a relatively similar response $(2.7 \%$ difference) in the visible range $(400-700 \mathrm{~nm})$ on transmission readings. However beyond the $700 \mathrm{~nm}$ range the variations in optical density become quite apparent with the film, which has been exposed to water producing a larger OD at these wavelengths of readout. These results show that a visible light densitometer such as the Vidar VXR-12 scanner would show a smaller difference in OD for the films compared to an infrared densitometer. By comparison of the films we can see a change in the absorption characteristics especially in the infrared region. These changes do however seem to be similar for exposures up to $1 \mathrm{~h}$ in water and seems relatively independent of whether the exposure has occurred before, during or after irradiation. These factors may prove useful if dosimetry, using EDR-2 film is needed in a water environment. A calibration method may not be compromised by water exposure. That is, the experiment could be performed in water and the calibration films exposed in dry conditions and placed in a water bath before processing to provide an accurate comparison of dose to within $\pm 3 \%$. From these results we would recommend that visible light is a more appropriate readout method for films which are in wet and dry states, and further, that infrared 


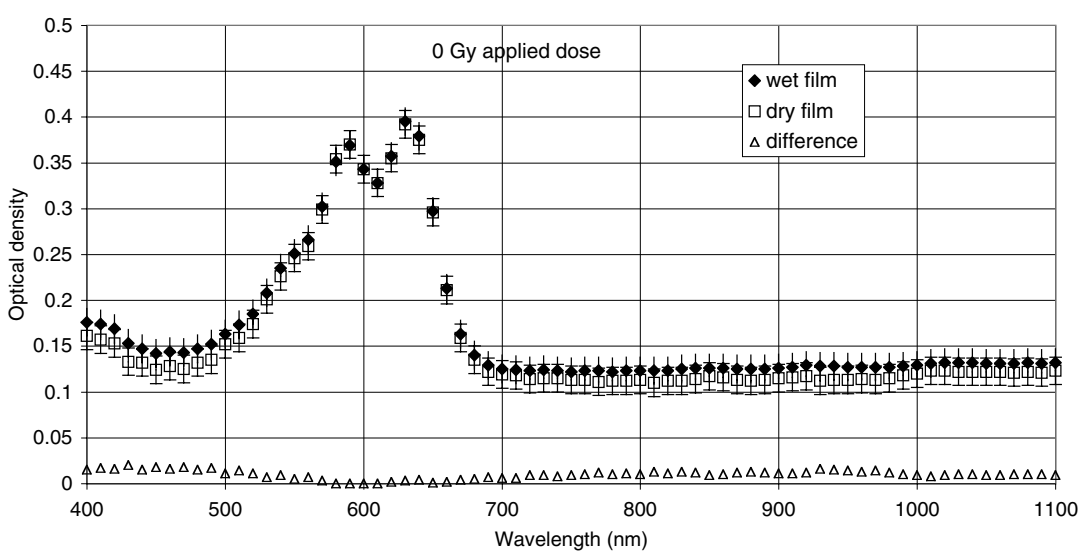

(a)

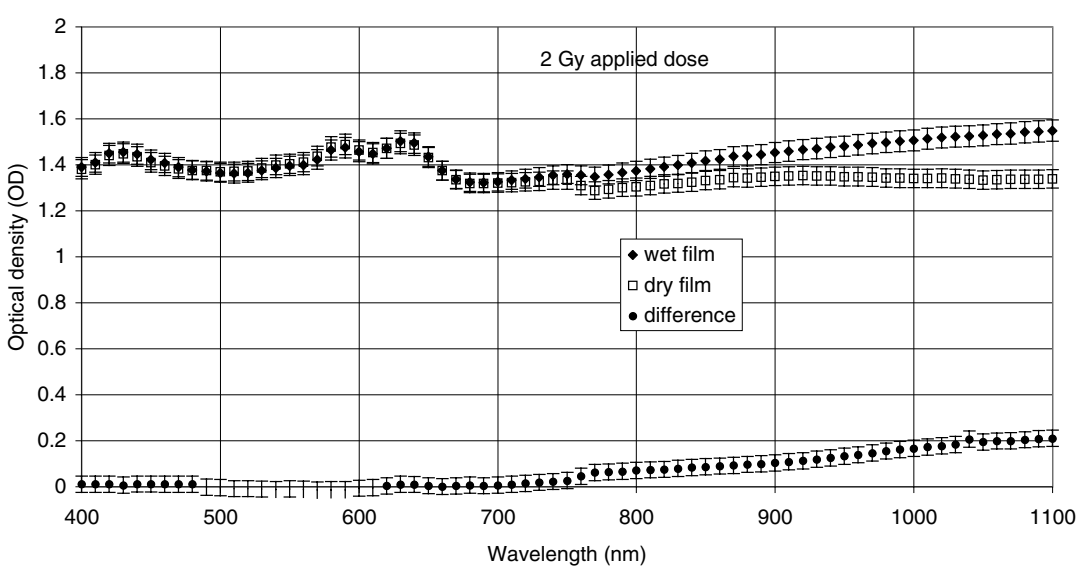

(b)

Figure 1. Optical density properties of wet (5 min soaking) and dry EDR2 radiographic film after (a) 0 Gy and (b) 2 Gy.

wavelengths will produce a significant difference between the two, especially at the higher wavelengths, and thus should be avoided.

\section{Conclusions}

Ready pack EDR-2 films provide a waterproof dosimetry medium and have been tested for water penetration for up to 2 days. If the EDR 2 film gets wet a change in absorption properties occurs but this effect is relatively independent of the time of water exposure up to $1 \mathrm{~h}$ and whether the water exposure occurs before, during or after irradiation. However care must be taken when processing 'wet' film to avoid pressure effects damaging the film due cohesive and adhesive forces between the film and insertion trays in automatic processing units.

\section{Acknowledgments}

This work has been fully supported by a grant from the Research Grants Council of HKSAR, China (Project No CityU 1012/01P). 


\section{References}

Johns H and Cunningham J 1983 The Physics of Radiology 4th edn (Springfield, IL: Charles Thomas)

Khan F 1992 The Physics of Radiation Therapy 2nd edn (London: Williams \& Wilkins)

Kron T, Duggan L, Smith T, Rosenfeld A, Butson M, Kaplan G, Howlett S and Hyodo K 1998 Dose response of various radiation detectors to synchrotron radiation Phys. Med. Biol. 43 3235-59

Mersseman B and De Wagter C 1998 Characteristics of a commercially available film digitizer and their significance for film dosimetry Phys. Med. Biol. 43 1803-12

Metcalfe P, Kron T and Hoban P 1997 The Physics of Radiotherapy X-rays from Linear Accelerators (Madison, WI: Medical Physics Publishing)

Suchowerska N, Hoban P, Davison A and Metcalfe P 1999 Perturbation of radiotherapy beams by radiographic film: measurements and Monte Carlo simulations Phys. Med. Biol. 44 1755-65

Suchowerska N, Hoban P, Butson M, Davison A and Metcalfe P 2001 Directional dependence in film dosimetry: radiographic and radiochromic film Phys. Med. Biol. 46 1391-7

Sykes J R, James H V and Williams P C 1999 How much does film sensitivity increase at depth for larger field sizes? Med. Phys. 26 329-30

van Battum L J and Heijmen B J 1995 Film dosimetry in water in a 23 MV therapeutic photon beam Radiother. Oncol. 34 152-9

Yeo I J, Wang C K and Burch S E 1997 A filtration method for improving film dosimetry in photon radiation therapy Med. Phys. 24 1943-53 